\title{
La legalidad y vigencia de las Entidades locales territoriales en el subsistema autonómico de la Región de Murcia
}

\author{
Antonio Martínez Marín \\ Catedrático de Derecho Administrativo
}

\begin{abstract}
Sumario: I. INTRODUCCIÓN. II. LEGISLACIÓN LOCAL. 1. Regulación estatal. 2. Regulación autonómica. III. ENTIDADES LOCALES INSTITUCIONALIZADAS: LOS MUNICIPIOS Y LAS MANCOMUNIDADES DE MUNICIPIOS. IV. ENTIDADES LOCALES NO INSTITUCIONALIZADAS EN LA COMUNIDAD AUTÓNOMA: PROVINCIAS, ÁREAS METROPOLITANAS, COMARCAS Y ENTIDADES LOCALES MENORES. V. REIVINDICACIONES DESCENTRALIZADORAS FRACASADAS: 1. Reivindicaciones municipales. 2. Reivindicación provincial. 3. Necrología de la primera propuesta comarcal de la Región. 4. La peculiar organización territorial-demográfica del municipio de Murcia. 4.1. Las Juntas de distrito y las Juntas vecinales como respuestas institucionales a la Ley estatal básica 7/1985, a la Ley autonómica local de desarrollo legislativo 6/1988 y a los Reglamentos de Juntas de distritos urbanos y Juntas de vecinos de pedanías. 4.2. Las medidas básicas de organización territorial de la Ley 57/2003 de modernización del Gobierno local. 4.3. El Reglamento vigente de participación ciudadana y distritos de 26 de mayo de 2005 como exigencia de la Ley 57/2003. VI. RELACIONES DE COLABORACIÓN DE LAS ADMINISTRACIONES LOCALES CON LA ADMINISTRACIÓN AUTONÓMICA: CONSORCIOS, CONVENIOS, PARTICIPACIÓN LOCAL EN ÓRGANOS CONSULTIVOS REGIONALES, Y SUBVENCIONES. VII. POST SCRÍPTUM: MANIFESTACIONES DEL ESPÍRITU POLÍTICO DEL SUBSISTEMA MURCIANO Y SUS SEMEJANZAS CON EL DEL SISTEMA ESTATAL.
\end{abstract}

\section{INTRODUCCIÓN}

Los 299 números de la Revista de Estudios de la Administración Local y Autonómica significan para mí cuanto menos una cifra igual de agradecimientos doctrinales de muy difícil nominación que, necesariamente, deben ser aumentados con los reconocimientos a sus directores y secretarios. En su primera nominación — Revista de Estudios de la Vida Local_ bebió de modo especial mi tesis doctoral «La representatividad municipal española», elaborada bajo la dictadura franquista y publicada posteriormente con la sentida dedicatoria «A nuestra querida España»,... a la que algunos nuevos políticos denominan desde hace dos o tres años «la España plural». Felizmente, ni mi conocimiento adquirido en la tarea sociológica-jurídica de las encuestas realizadas a más de trescientos vecinos de 27 municipios españoles, de todas las regiones, durante cuatro meses de los años 73-74 y de los 7.000 kilómetros recorridos; ni la historia de los últimos siglos; ni la Constitución de 1978 —ni ninguna otra, salvo olvido, pues todas ellas saben de mi lectura-; ni los cientos de artículos leídos en la REALA me permiten adjuntarle el artículo y el adjetivo de moda. 
Dado que mis raíces académicas se encuentran en la vida local y el primer amor no se olvida, no he encontrado otro regalo más preciado para el número 300-301 —o en su prolongado 302 - que este estudio sobre la legalidad y vigencia de los Entes locales en mi propia Comunidad Autónoma.

La metodología empleada para este número histórico responde a la de un realismo jurídico un tanto inhabitual en nuestra tradición doctrinal, pues la temática local estudiada no se limita a la mera exposición exegética formal de las normas concretas, sino que, más allá del comentario al uso, se procura analizarlas en la comprensión de su nacimiento y vigencia, incluso de su gestación abortada. No se ofrece una sociología local-autonómica sino una añadida elemental dación de cuentas de su vigencia u operatividad. En este sentido, se pretende tanto una descripción fáctica de nuestras Entidades como el intento de la lúcida penetración social y política comprensiva de ellas que, en tan alto grado, logró Tocqueville sobre las instituciones francesas y estadounidenses y que en el mejor estilo francés nos dejó escritas, respectivamente, en sus obras «El Antiguo Régimen y la Revolución» - L'Ancien Régime et la Révolution - y «De la Democracia en América» —De la Démocratie en Amérique-.

Este tratamiento metodológico está imantado también de las referencias geográficas, históricas, sociales y, sobre todo, del espíritu que debe presidir la democracia y que no es otro que el imprescindible amor por el interés general que debe presidir el sistema democrático. De nuevo es otro francés universal quien logró amasar todos estos datos y otros más para ofrecérnoslos en «Del Espíritu de las Leyes» -De l’Esprit des lois-. De semejante modo se ha intentado incorporar en este breve estudio elementales manifestaciones del espíritu público que traslucen nuestros políticos del subsistema murciano y pergeñar algunas conexiones con sus homólogos del sistema estatal.

El jurista alemán Ihering explica el tercer bastión doctrinal que alienta este artículo crítico - pretendidamente dotado en este caso del análisis del problema y de su solución doctrinal—, pues de él he aprendido que «La Lucha por el Derecho» - Der Kamf ums Recht- debe ser para el jurista una condición biológica de la poesía de su carácter y por consiguiente no sujeta a límite temporal ni éxito puntual obtenido. Mi lucha jurídica-ciudadana ha sido la del advenimiento y perfeccionamiento de un Estado de Derecho policéntrico para España. Este artículo, en último término, es un intento de perfeccionar el ordenamiento jurídico mejor que ha conocido la historia de España con la Constitución de 1978, ciertamente imperfecta y necesitada de reforma; pero fundada en un consenso que, aunque de oportunidad y de cuestiones orilladas, ha producido los mejores frutos de los últimos siglos y, sobre todo, ha posibilitado la construcción, con las consabidas imperfecciones y lagunas, de todo un ordenamiento jurídico estatal asentado en la Norma Constitucional, hoy en solapado entredicho y simulado quebranto formal y, sobre todo, espiritual por la ruptura del tenue e imperfecto consenso que la sostenía. 
LA LEGALIDAD Y VIGENCIA DE LAS ENTIDADES LOCALES TERRITORIALES...

Debo finalmente confesar a cualquier lector de este estudio crítico que, respetando otras opciones, pertenezco, como así lo recomendaba Santiago Ramón y Cajal en «Los tónicos de la voluntad», al grupo de profesores universitarios que no han hecho de su condición académica «un mero escabel para la política o un decoroso reclamo de la clientela profesional».

\section{LEGISLACIÓN LOCAL}

\section{Regulación estatal}

La Constitución de 1978 establece y garantiza la existencia preceptiva de las Entidades locales territoriales del municipio, la provincia y la isla, y a la vez dispone que su respectivo gobierno y administración será el Ayuntamiento o Concejo Abierto, la Diputación u otras instituciones de carácter representativo, y los Cabildos o Consejos. La expresión alternativa a la Diputación de «otras instituciones de carácter representativo» no supone la constitucionalización del carácter contingente de la Diputación, sino que, según la ortodoxa interpretación constitucional de este fragmento de Rafael Entrena, «se pretende obviar el problema de la denominación de los órganos representativos interinsulares provinciales y al mismo tiempo se soslayan problemas terminológicos en relación con la denominación de las Corporaciones provinciales en Navarra, Vizcaya, Guipúzcoa y Álava» ${ }^{1}$.

En puridad, la provincia como Entidad local y la Diputación como su gobierno y administración no existe en las provincias de Álava, Guipúzcoa y Vizcaya en la medida que su foralidad se encuentra contemplada en la disposición adicional primera de la CE. Ésta ampara y respeta los derechos de sus territorios históricos y, en consecuencia, son las Diputaciones forales los órganos de gobierno y administración de sus territorios históricos, que coinciden con los límites de las tres provincias mencionadas.

Junto a esta excepción foral de la provincia como Entidad local, hay que adjuntar las de las dos canarias, pues en esta Comunidad Autónoma insular tampoco existe aquélla como Entidad local ni su órgano representativo de la Diputación. En una estricta interpretación literal del número 4 del artículo 141 de la CE — «En los archipiélagos, las islas tendrán además su administración propia en forma de Cabildos o Consejos»- debería presumirse la existencia de dos Diputaciones provinciales para las dos provincias atlánticas; sin embargo, una interpretación histórica y lógica ha determinado su inexistencia y su sustitución peculiar en cada una de las islas por sus correspondien-

\footnotetext{
1 Entrena Cuesta, R., Comentarios al artículo 141, en Fernando Garrido Falla, Comentarios a la Constitución, tercera edición, Civitas, 2001. El comentario realizado por este autor me exime reiterar el carácter constitucional preceptivo de la provincia y de la Diputación como su gobierno y administración.
} 
tes siete Cabildos. Ha sido el Estatuto de Autonomía canario quien en su disposición sexta suprime las mancomunidades provinciales interinsulares y transfiere sus competencias y recursos materiales y personales a la Comunidad Autónoma. La conclusión es que, aun comprendiendo las salvedades mencionadas y el posible desconocimiento del hecho insular por los constituyentes, la supresión de la Diputación local en las provincias canarias vulnera formalmente la Constitución.

Finalmente y como es bien sabido, las siete Comunidades Autónomas uniprovinciales - Asturias, Islas Baleares, Cantabria, La Rioja, Madrid, Murcia y Navarra - suprimen sus respectivas Diputaciones y subrogan en favor del gobierno y administración autonómica sus competencias y medios personales y materiales.

El nuevo Estatuto catalán² suprime las Diputaciones provinciales y, de conformidad con su artículos 2 y sobre todo el 90.3 - «Los Consejos de veguería sustituyen a las Diputaciones»— excepciona también a la provincia como Entidad local representada por la Diputación. El nuevo Estatuto, más sutil que el de 1979, vertebra el territorio catalán en veguerías, comarcas y municipios; mientras que el primero sólo lo hacía sobre comarcas y municipios. Esta duplicidad y el intento de suprimir las Diputaciones provinciales fue la causa determinante de que la STC 32/1981 inconstitucionalizara la Ley catalana 6/1980 de transferencia urgente y plena de las Diputaciones catalanas a la Generalidad y salvase de este modo jurisprudencial la vida de éstas. Parcialmente, este mismo problema se plantea de nuevo con la Ley valenciana 2/1983 y es también el TC quien con su sentencia 27/1987 mantiene el carácter preceptivo de la provincia como Entidad local. Estas consideraciones conllevan a la afirmación de que la sustitución de la provincia como Entidad local por las veguerías es inconstitucional y, además, contradice de modo manifiesto la jurisprudencia constitucional. Más aún, la creación de los Consejos de éstas a fin de sustituir a las Diputaciones provinciales han resquebrajado la más genuina y propia división territorial local de Cataluña: los municipios y las comarcas.

He aquí pues la generalidad, las excepciones, los conflictos y, en su caso, la inconstitucionalidad formal canaria; aunque apoyada en una interpretación lógica a favor de la supresión de la provincia como Entidad local preceptiva constitucionalizada al amparo del artículo 141.4.

\footnotetext{
${ }^{2}$ El Estatuto no menciona en su preámbulo el vocablo reforma, sino la declaración de la «expresa voluntad de ser y de seguir avanzando en el reconocimiento de su identidad colectiva y en el perfeccionamiento y la ampliación del autogobierno mediante este nuevo Estatuto». Esta novación se confirma, además, con la proclamación de Cataluña como nación en el artículo 1, y con los nuevos 223 artículos del nuevo Estatuto frente a los 57 sustituidos del derogado de 1979. Puede afirmarse que -sin ofrecer otras referencias de presunta inconstitucionalidad por exigencia temática- que la nueva Norma catalana está fuera de la Constitución de 1978, pues ésta contempla y posibilita la reforma estatutaria en sus artículos 147 y 148, mas no la dación de nuevos Estatutos «progresivos» en la ampliación de su autogobierno e identidad como nación catalana diferente de la española.
} 
LA LEGALIDAD Y VIGENCIA DE LAS ENTIDADES LOCALES TERRITORIALES...

Esta referencia de la garantía de la provincia como Entidad local preceptiva se formula desde la exigencia establecida en la CE y del refrendo dado por el Tribunal Constitucional en la mencionadas sentencias 32/1981 y 27/ 1987; aunque desde una consideración doctrinal mantengo mi discrepancia al respecto como así lo escribía en 1986 con la literalidad siguiente: «Ante la institucionalización preceptiva de la provincia como Entidad local, su rechazo como tal o dejar su existencia y configuración a la libre voluntad de las Comunidades Autónomas, la Constitución ha optado por la primera opción...; sin embargo, la tercera hubiera sido la más sabia desde la racionalidad organizativa del nuevo sistema de las autonomías» ${ }^{3}$. Los conflictos mencionados, las quiebras referidas, la racionalidad organizativa y la debilidad competencial de las Diputaciones avalan esta opción propuesta ante la necesaria reforma de la Constitución de 1978.

Finalmente, el artículo 141.3 dispone la creación facultativa de agrupaciones de municipios diferentes de la provincia y faculta al legislador estatal la opción por otras Entidades locales de existencia contingente.

El Estado, ejerciendo su competencia exclusiva conferida por el artículo 149. 1. $18^{\circ}$ para establecer las bases de las Administraciones públicas, dicta la Ley 7/1985 reguladora de las Bases del Régimen Local. Este texto legal básico ha institucionalizado, en coherencia constitucional, como Entidades locales preceptivas para toda España al municipio, la provincia y a las islas; y con existencia facultativa a las Entidades que puedan crearse por agrupaciones de municipios diferentes de la provincia. La Ley 7/1985 ha nominado estas posibles Administraciones supramunicipales con las denominaciones de comarcas, áreas metropolitanas y mancomunidades de municipios; y no ha omitido la referencia a las facultativas entidades inframunicipales que, bajo la genérica denominación de Entidades locales menores, deberán regular las Comunidades Autónomas como administración descentralizada municipal de núcleos de población separados, bajo denominaciones tradicionales de caseríos, parroquias, aldeas, barrios, anteiglesias, concejos, pedanías, lugares, anejos, y otros análogos.

\section{Regulación autonómica murciana}

La regulación general de las Entidades Locales de esta Comunidad se encuentra contenida en tres textos legales: el Estatuto de 1982 y las Leyes 6/1988 de Régimen Local y 7/1983 de Descentralización y Colaboración entre la Comunidad Autónoma y las Entidades Locales. El primero de éstos organiza territorialmente en su artículo 3 a la Comunidad Autónoma en municipios y comarcas con carácter preceptivo, concurrente e integral; y en man-

\footnotetext{
${ }^{3}$ Martínez Marín, A., Derecho Administrativo. La organización administrativa, Tecnos, 1986, p. 306 y ss.
} 
comunidades de municipios, áreas metropolitanas y entidades locales menores o inframunicipales con existencia facultativa. La Ley de Régimen Local de la Región de Murcia, dictada en ejercicio de la competencia estatutaria de desarrollo legislativo y ejecución establecida en el artículo 11.9 en materia de régimen local, reitera las Entidades Locales mencionadas y regula el procedimiento de creación y, en su caso, de funcionamiento de los mencionados Entes. Y el tercer texto legal mencionado contiene los principios y los instrumentos de relación entre las Administraciones murcianas.

\section{ENTIDADES LOCALES INSTITUCIONALIZADAS: LOS MUNICIPIOS Y LAS MANCOMUNIDADES DE MUNICI- PIOS}

La realidad organizativa local en esta Región de 24 años de autonomía es la de 45 municipios y 8 mancomunidades, 6 de servicios sociales y 2 de servicios turísticos.

La creación de municipios es una competencia autonómica, aunque condicionada por la Ley estatal básica 7/1985 a tres exigencias ineludibles: la nueva Entidad sólo podrá crearse sobre la base de núcleos de población territorialmente diferenciados, siempre que los municipios resultantes cuenten con recursos suficientes para el cumplimiento de las competencias municipales y no suponga disminución de los servicios que venían siendo prestados. A los tres requisitos estatales genéricos para la creación de todo municipio español, considerados constitucionales por el TC en su sentencia 214/ 1989, la Ley de desarrollo legislativo murciana 6/1988 adjunta un cuarto: la necesidad de justificar que la creación por segregación debe comportar una mejora objetiva en la prestación de servicios en el nuevo municipio - el artículo 11.2 dispone que «...es preciso, asimismo, justificar que la segregación comporta una mejora objetiva en la prestación de los servicios del nuevo municipio»- Esta añadida exigencia es una manifestación del espíritu centralista autonómico que viene a dificultar la creación de nuevas municipalidades en la medida que establece un nuevo requisito pro futuro difícil de demostrar y de gran discrecionalidad valorativa. De este modo se ha agravado el derecho constitucional de acceso a la autonomía municipal de los habitantes de potenciales municipios y, en coherencia, debería derogarse esta indeterminada exigencia establecida por el legislador autonómico murciano.

Adoptando la regulación tradicional de la legislación local centralista española, la referida Ley autonómica ha integrado el procedimiento de creación del nuevo municipio como una más de las modalidades de alteración de los términos municipales, ya sea ésta por segregación, fusión o incorporación. $\mathrm{Y}$, en este sentido, su artículo 14 ha dispuesto que la iniciación de los expedientes de dicha alteración se realizará por el órgano de la Administración regional competente, ya de oficio o ya a instancia de cualquiera de los Ayun- 
LA LEGALIDAD Y VIGENCIA DE LAS ENTIDADES LOCALES TERRITORIALES...

tamientos interesados o de la Administración del Estado a través de su Delegado del Gobierno; mientras que con carácter voluntario podrá iniciarse por acuerdo de los Ayuntamientos interesados y, en el supuesto de segregación parcial para crear un nuevo municipio, a petición de la mayoría de los vecinos residentes en la parte o partes del territorio que pretenda segregarse. En concreto, el procedimiento creativo voluntario suele iniciarse con las firmas peticionarias de la mayoría de los residentes del núcleo o núcleos segregacionistas, la audiencia de los Ayuntamientos afectados, la información pública durante el plazo de un mes, el preceptivo informe del supremo órgano consultivo autonómico y el obligado comunicado, en el caso de nacimiento de nuevo municipio, a la Administración del Estado. Obviamente, el Gobierno autonómico podrá denegar o aceptar la solicitud, en cuyo supuesto deberá resolver dicho expediente mediante su publicación a través de decreto. En todo caso, siempre queda expedita la vía jurisdiccional para que cualquiera de las partes interesadas en desacuerdo con la resolución dada pueda interponer el pertinente recurso contencioso-administrativo.

Esta demanda derogatoria de la exigencia mencionada o, dada su constitucionalidad reconocida por la jurisprudencia del Tribunal Supremo en su sentencia de 15 de marzo de 2005, debería concretarse con una exigencia precisa y determinada, como puede ser el de un informe sustentado por un experto independiente en organización y financiación de servicios municipales nombrado de común acuerdo por las partes segregada y segregante. Debo adjuntar la propuesta de una modificación de la mayoría establecida de firmas de los vecinos por otra cualificada de al menos tres quintos de la población; pues al tratarse de una decisión de suma trascendencia quedaría asegurada de este modo una voluntad consistente de la independencia municipal a fin de que ésta ya no quede al socaire de un cambio volitivo mínimo de la mutable voluntad vecinal.

La cifra actual de los 45 municipios murcianos — de ellos, el de Murcia y el de Cartagena están dotados de la organización de los de gran población (este último por la Ley regional 5/2005, de 20 de junio)— no sólo es la más baja de las Comunidades Autónomas de España, sino que resulta ser considerablemente inferior a la de los 2248 de Castilla y León; aunque la población de esta Región - 1.335.792 - la sitúa en el noveno lugar de las 17 españolas, incluso con mayor censo de habitantes que las pluriprovinciales Extremadura -1.083.879- y Aragón - 1.269.027-. La municipalidad capitalina -409.810- ofrece un tercio de habitantes del censo regional, evidenciando de este modo un acusado desequilibrio entre la población y el territorio; pese a que sólo dos de estos Entes locales, Ulea — 959- y Ojós —976- tengan menos de 1000 habitantes, proporción que la sitúa también, junto a Canarias, en la Comunidad con menos municipios de pequeña población de las españolas ${ }^{4}$.

\footnotetext{
${ }^{4}$ Población de los municipios españoles, INE, 2005.
} 
Las mancomunidades de municipios inician su procedimiento creativo con el acuerdo mayoritario de los respectivos Ayuntamientos y la elaboración de un Proyecto de Estatutos que, sometido a la información pública y de la Consejería autonómica correspondiente, debe ser aprobado por las mencionadas Corporaciones y posteriormente publicado en el BORM.

Las mancomunidades de servicios sociales, mayoritariamente, se constituyen en los años 1990 y 1991, agrupan a unos 25 municipios y su finalidad es la prestación de los servicios mencionados que, ubicados en un Centro, atienden las necesidades vecinales de los Entes integrados. Generalmente la mancomunidad trae causa de la imposibilidad o dificultad de prestar individualizadamente estas funciones sociales que suelen concretarse en servicios de atención temprana y de ayuda a domicilio, a la inmigración, a la drogodependencia, a las familias desfavorecidas, disponiendo, en ocasiones, de Centro ocupacional y/o residencia de discapacitados. Los presupuestos son variables y pueden oscilar entre el medio y el millón y medio de euros.

Las dos mancomunidades de servicios turísticos son las del Mar Menor y la de Sierra Espuña, constituidas respectivamente en 1992 y 2001 e integradas por cuatro y cinco municipalidades que tienen como finalidad la promoción turística de las respectivas zonas marítima y de montaña; ya con inversiones en infraestructuras, formación del personal de los establecimientos turísticos, inspección y control del estado de las playas, etc., en el primer caso; y en el segundo con un plan de señalización de toda esta sierra, rehabilitación del mayor número de inmuebles ubicados en ella, establecimiento de puntos de información, etc. Los presupuestos respectivos están integrados por las correspondientes partidas municipales, pero también por subvenciones del Estado y de la Comunidad Autónoma; y sus cifras presupuestarias también son bajas en cuanto la primera dispone de menos de un millón y la segunda de poco más de 550.000 euros $^{5}$.

Comparativamente, este asociacionismo municipal de nuestra Comunidad se encuentra por debajo de la media nacional que ofrece una cifra global de 984 mancomunidades, según el Registro de Entidades Locales; y así mismo debe destacarse los dos únicos servicios determinantes de su constitución, como son los sociales y los turísticos, frente a otros muchos de los centenares de esta Entidades constituidas en la geografía española, que si ciertamente tienen alguna de estas dos actividades, como objetivo servicial determinante, también la prestación de otros servicios muy variados motiva la existencia mancomunada y que, como ha nominado Sosa Wagner, son tanto los de incendios, recaudación, urbanismo, informatización, obras públicas, recogida y tratamiento de basuras, aprovechamientos forestales, abastecimiento de

\footnotetext{
${ }^{5}$ Hay que dejar constancia de la existencia de algunas otras mancomunidades de municipios para la prestación de servicios sociales, pero actualmente han sido suprimidas por razones diversas como la capacidad prestacional individualizada de algunos de sus municipios, la separación geográfica entre ellos o también las desavenencias surgidas entre las correspondientes corporaciones.
} 
LA LEGALIDAD Y VIGENCIA DE LAS ENTIDADES LOCALES TERRITORIALES...

aguas, sostenimiento del cuartel de la Guardia Civil, como los de alumbrado público, mataderos, mercados, planes urbanísticos, medio ambiente, aprovechamiento de pastos, servicios de pistas de esquí, gestión del mercado de frutas y verduras, y limpieza ${ }^{6}$.

En puridad, este asociacionismo es bastante débil; pues el de las mancomunidades sociales puede ser considerado como obligado, mientras que el de las dos turísticas se encuentra mantenido por las pequeñas ayudas y subvenciones del Estado y de la Comunidad Autónoma.

\section{ENTIDADES LOCALES NO INSTITUCIONALIZADAS EN LA COMUNIDAD AUTÓNOMA: PROVINCIAS, ÁREAS METROPOLITANAS, COMARCAS Y ENTIDA- DES LOCALES MENORES}

Así pues, esta Comunidad Autónoma uniprovincial no ofrece en el momento actual las Entidades Locales de la provincia, comarca, área metropolitana y entidad local menor. En relación con la primera hay que recordar solamente que la Diputación provincial se disuelve por el Estatuto de Autonomía de 1982, de conformidad con las prescripciones establecidas en su artículo 18 y disposiciones transitorias, especialmente en la segunda, número 2; y sus competencias, medios personales y materiales quedan integrados en la nueva Administración autonómica. Esta supresión, asumida hoy pacíficamente como lógica y necesaria, no gozaba de una posición doctrinal y política compartida en los años previos a la disolución estatutaria, pues incluso la Constitución había institucionalizado la provincia como Entidad Local con carácter preceptivo general en el artículo 141. No obstante, con anterioridad al Supremo Texto de 1978 y al Estatuto de Murcia de 1982, el autor de estas páginas había publicado en 1977 de modo claro y sin reserva circunstancial alguna que: «En un futuro regionalismo murciano la Diputación debe desaparecer» ${ }^{7}$.

Respecto al área metropolitana hay que expresar, junto al dato de su inexistencia, que debe ser creada por ley de la Asamblea Regional y que su procedimiento constitutivo puede iniciarse tanto por los propios municipios como por el Consejo de Gobierno de la Comunidad. No nos consta que hasta el

\footnotetext{
${ }^{6}$ Véase, Sosa Wagner, F.: «Mancomunidades y otras formas asociativas», en S. Muñoz Machado (director), Tratado de Derecho municipal, vol. I, segunda edición, Civitas, 2003, p.1215.

\begin{abstract}
7 Martínez Marín, A.: El Regionalismo Murciano, Pliegos 23/27, mayo de 1977, Murcia, p. 28. Un tratamiento doctrinal de la provincia en las Comunidades Autónomas pluriprovinciales resulta metodológicamente improcedente en este trabajo; no obstante del papel difuso y desubicado de la provincia en el actual Estado autonómico así como de su «vacuidad» competencial se viene ocupando la doctrina, de la que a título de ejemplo se menciona el artículo de CARBALLERIA, $\mathrm{M}^{\mathrm{a}}$. T.: «iSe han convertido las provincias en un simple nombre», Revista de Estudios de la Administración Local, número 289, 2002, pp. 9-35.
\end{abstract}


momento presente estas iniciativas se hayan producido en nuestra Comunidad Autónoma. Como dato complementario hay que manifestar que el número de áreas metropolitanas en España es, salvo error, de cuatro: dos en Barcelona - Entidades metropolitanas de transporte, y de servicios hidráulicos y tratamiento de residuos - y las dos restantes están en Valencia - Entidades metropolitanas para el tratamiento de residuos, y de servicios hidráulicos-. La conclusión obvia es que actualmente esta Entidad local es la que ofrece un número destacadamente menor de todas ellas.

La descentralización en ámbitos territoriales inferiores del municipio se encuentra prevista en el artículo 3 del Estatuto de autonomía y articulada en sus extremos institucionales - procedimiento de creación, organización, competencias, y medios personales y patrimoniales - en la Ley 6/1988, de Régimen Local, con la denominación de entidades locales menores. De nuevo hay que recordar la inexistencia en la Comunidad de estas Entidades; no obstante, dada la cifra de sólo 45 municipios hay un gran número de núcleos de población separados del de la capitalidad municipal, que en el caso de Murcia se denominan pedanías. La estructura socio-espacial heredada de esta municipalidad era el de un casco capitalino rodeado por unas cincuenta pedanías, enclavadas y separadas por la huerta del río Segura: un modelo de ciudad, en esencia, que repartía aproximadamente por mitad su población entre el centro y la vertebrada periferia. Estas denominadas pedanías eran y son mayoritariamente inequívocos pueblos que me merecieron, en la lejanía de 25 años, la calificación «de auténticas comunidades en razón del número de sus habitantes, deslinde territorial e idiosincrasia peculiar diferenciada»; y a las que había que institucionalizar, al menos las de mayor población, como entidades locales menores en un proceso gradual y consensuado. Aun hoy se mantiene esta propuesta, fortalecida por la existencia de 27 pedanías con población superior a 3000 habitantes, 6 con unas cifras elevadas de 7000 y 2 de ellas sobrepasan las de 15.000; aunque la exigencia de la separación física entre éstas y el núcleo capitalino va desapareciendo como consecuencia del incontrolado desarrollo urbanístico ${ }^{8}$.

Ciertamente, algunos de estos pueblos separados y con población superior a los 10.000 habitantes han reivindicado en ocasiones esta institucionalización; pero estos movimientos espontáneos no han prosperado ante el centralismo del Ayuntamiento murciano y de los dos partidos políticos mayoritarios autonómicos, contrarios al envite descentralizador, a pesar de la vigencia en el ordenamiento jurídico murciano de la Ley 7/1983, de 7 de octubre, de Descentralización Territorial y Colaboración entre la Comunidad Autónoma y las Entidades Locales. De nuevo hay que completar esta referencia con dos datos: el primero de ellos es, como escribe P. Menéndez, la escasa atención que han recibido estas Entidades por parte de la

\footnotetext{
${ }^{8}$ Martínez Marín, A.: Bases para un sistema autonómico comunitario del municipio de Murcia, Editora Regional de Murcia, 1981, pp. 41-62, (la cita se encuentra en la p.61).
} 
LA LEGALIDAD Y VIGENCIA DE LAS ENTIDADES LOCALES TERRITORIALES...

doctrina ${ }^{9}$, y el segundo es la importancia numérica de ellas en España al contabilizar 3.696, de las que sólo las Comunidades de Canarias y Murcia no cuentan con ninguna.

\section{REIVINDICACIONES DESCENTRALIZADORAS FRACA- SADAS}

\section{Reivindicaciones municipales}

Este primer epígrafe da cuenta de los fracasos de creación de dos nuevos municipios y de los tres procedimientos independentistas en tramitación. El primero de estos fracasos refiere la creación de la nueva Entidad municipal de «Dos Mares», integrada por los núcleos de población de Los Belones, Cabo de Palos, La Manga del Mar Menor, Cala Reona, Playa Honda, Mar de Cristal, Islas Menores, Cobaticas, Las Barracas y algunas islas adjuntas. La sentencia 197/2000 del Tribunal Superior de Justicia de Murcia mantiene la validez del Decreto denegatorio 42/1997 y estima los argumentos de los demandados - Comunidad Autónoma, Cartagena y San Javier- en razón de dos requisitos incumplidos: la ausencia de la mayoría de los residentes de algunos de los núcleos peticionarios de la independencia municipal, y la omisión del requisito demostrativo de la mejora de los servicios municipales que la nueva Entidad ofrecería sobre los prestados por los de Cartagena y San Javier. La sentencia del Tribunal Supremo de 15 de marzo de 2005 desestima el consiguiente recurso de casación y condena en costas al recurrente.

El segundo supuesto denegado ha sido el de la creación del nuevo municipio «El Algar del Mar Menor», integrado por El Algar, Lentiscar y parte de El Beal. La sentencia del Tribunal Superior de Justicia 253/2001 de 26 de abril desestima el recurso interpuesto por la Asociación actora contra el Decreto 55/ 1998 de ocho de octubre y, en este caso, en base al incumplimiento de tres de los requisitos legales establecidos: ausencia de mayoría de los residentes en algunos de los núcleos, infundada demostración de los recursos económicos financieros suficientes para el mantenimiento de la nueva Entidad municipal, y la carencia del requisito de la obligada superior calidad de los futuros servicios sobre los prestados por el municipio de Cartagena. El Tribunal Supremo considera inadmisible el recurso de casación en su sentencia de 17 de junio de 2004 e impone las costas a la parte recurrente.

Junto a estos dos proyectos frustrados momentáneamente de nuevas municipalidades en los términos de Cartagena y San Javier, han iniciado ya este procedimiento de creación los pueblos de El Palmar y de El Raal, pertene-

\footnotetext{
9 Menéndez, P.: «Las Entidades de ámbito inferior al municipio», en S. Muñoz Machado (director), Tratado de Derecho municipal, ob. cit., p.1179. Es obligado citar a GuIRADo CiD, C.: «Las Entidades Locales Menores: antecedentes legislativos y regulación actual. Régimen murciano», Anales de Derecho, Universidad de Murcia, número 11, 1991, pp.237-258.
} 
cientes al municipio de Murcia; y Almendricos al de Lorca. Todos ellos distanciados de la capitalidad en ocho, diez y veinte kilómetros aproximados, con núcleos urbanos separados y con poblaciones de 19.399, 5.564 y 1.649 habitantes. Otros movimientos vecinales ya han comenzado a levantar sus voces «pro propio Ayuntamiento», pero carezco de noticia alguna de fase iniciada del procedimiento.

La conclusión estadística es que no se ha creado ni suprimido municipio alguno en la Región, a excepción del de Los Alcázares en 1983. No obstante, ha sido necesario dejar constancia de estas reivindicaciones, de la negativa de los respectivos municipios y del Gobierno de la Comunidad Autónoma, y de la ausencia de entendimiento alguno entre los protagonistas para buscar fórmulas organizativas inframunicipales adecuadas. En este sentido y con conocimiento de su realidad poblacional, Cantabria y Castilla-La Mancha han dictado sus específicas Leyes de Entidades Locales Menores 6/1994 y 3/1991.

Como puede deducirse, esta reivindicación de nuevas Entidades locales municipales y, en su caso, inframunicipales no se encuentra cerrada; y la mera posición conservadora negativa de los municipios y del Gobierno de la Comunidad Autónoma - y que es la de los dos partidos políticos mayoritarios y de facto únicos - no demuestra talento organizativo alguno para dar una solución de entendimiento a los problemas organizativos planteados ante la obvia y notoria deficiencia de los servicios públicos municipales prestados a estas poblaciones actoras de la protesta institucional. Más aún, si la «atención» recibida no fuera hasta insultante difícilmente se hubieran producido estas reivindicaciones vecinales por parte de una colectividad regional dominada por el desinterés de los asuntos públicos. En un sentido concreto y a nuestro juicio, el futuro demostrará de modo más fehaciente todavía la necesidad imperiosa del potencial municipio de «Dos Mares» ante la desidia servicial, sobre todo en la recogida de basuras y limpieza de playas, y despropósito urbanístico que ha venido padeciendo, de modo especial, La Manga del Mar Menor, prodigio singular de la naturaleza y, sin embargo, partida administrativamente entre los dos municipios de Cartagena y San Javier, distanciada respectivamente de sus capitalidades en más de treinta y cuarenta kilómetros, con una población de 4.147 residentes que unidos a los 1.111 de la ya geográficamente «unida» Cabo de $\mathrm{Pa}$ los suman una población censal de 5.198 personas; pero esta cifra es engañosa porque hay varios miles más de personas transeúntes ocasionales y que en época estival alcanza entre los 150.000 o 200.000 veraneantes. Finalmente, si La Manga del Mar Menor no se garantiza una determinada cifra de población turística estable es de presumir que su decadencia se irá acentuando año tras año. Estas consideraciones elementales han determinado la defensa concreta de la futura municipalidad de «Dos Mares» integrada, al menos inicialmente, por La Manga y Cabo de Palos; pero ha sido el interés general por preservar este singular regalo de la naturaleza a fin de que toda persona 
LA LEGALIDAD Y VIGENCIA DE LAS ENTIDADES LOCALES TERRITORIALES...

de cualquier nacionalidad se sienta enriquecida en cuerpo y espíritu con su visita $^{10}$.

\section{Reivindicación provincial}

El Pleno del Ayuntamiento de Cartagena en sesión de 28 de diciembre de 1979 debatía y aprobaba una moción del Partido Cantonal sobre la provincialidad de esta ciudad. El portavoz de esta formación electoral fundamentaba la creación de una nueva provincia en su singularidad histórica, geográfica, social, industrial, etc.; pero sobre todo resaltaba las ventajas generales que para la futura Comunidad Autónoma tendría esta creación: mayor representación en las Cortes y un aumento en las subvenciones provinciales del Estado. La reivindicación se formulaba, reconocía de modo expreso este concejal, sin la existencia de estudio previo alguno sobre la viabilidad y conveniencia de su propuesta. El Partido Socialista, a través de su Alcalde, mostraba su apoyo a la mencionada moción, aun reconociendo éste su autoría en una anterior propuesta de un Estatuto para la Comarca de Cartagena; no obstante y en esta ocasión cambiaba su pensamiento al respecto con las inequívocas palabras reflejadas en el acta: «Estoy dispuesto a apoyar la moción y luchar por la provincia de Cartagena». Los concejales de la oposición integrada por Unión de Centro Democrático y Partido Comunista se abstienen de pronunciarse ante la ausencia del referido estudio y, en consecuencia, carentes de la información imprescindible para apoyar la provincialidad. La votación cuantificaba 13 votos a favor y 11 abstenciones que, como es de presumir, se correspondía respectivamente con el gobierno socialista-cantonal, y con la oposición centrista-comunista. El Estatuto de Autonomía se aprobaba tres años después sin texto y sin lucha socialista alguna por la nueva provincia; mientras que la Comunidad Autónoma se organizaba territorialmente en comarcas y municipios.

Las sesiones plenarias de 30 de junio de 1997 y de 5 de marzo de 1998 replantean de nuevo este tema. En la primera de éstas y ante 32.489 firmas recabadas por la formación Cantonal, ahora sin representación alguna en la Corporación, se reivindica el pronunciamiento corporativo sobre «la petición

\footnotetext{
${ }^{10}$ La convicción expresada me obliga en coherencia a la discrepancia con la posición mantenida por la parte recurrente en el proceso judicial perdido. En mi opinión, la petición segregacionista fue excesivamente expansiva, pues debería haberse limitado a las poblaciones de Cabo de Palos y de la Manga, y haber resaltado que aun su estricta población censal supera a la del 95 por ciento de los municipios españoles; y haber acompañado, como así lo ha señalado el Tribunal Supremo en la correspondiente Sentencia recaída, un informe -o incluso dos- realizado por un experto en economía y financiación de servicios municipales demostrativo en abundancia de la mejora objetiva de los nuevos servicios sobre los deficientes actuales. Debo adjuntar, a fuer de sinceridad, que mi posición no descansa en la espera de Godot ni descarta la llegada de Murphy, sino en la lucha por este Derecho y por esta Naturaleza concretos. Los futuros ediles de La Manga bien pueden ser defensores y, en su caso, restauradores del «paraíso perdido» o unos vulgares «mangantes» que precipiten aún más el estado de destrucción actual.
} 
de una consulta popular para la iniciación de los trámites para constituir la provincia de Cartagena». La propuesta es rechazada por los grupos popular y socialista y admitida por los tres votos concejiles del grupo Izquierda UnidaLos Verdes, en base a un informe jurídico municipal prohibitivo de la consulta que contaba, además, con el rechazo previo de los seis municipios afectados por el Proyecto provincial. Ante la proximidad de las elecciones locales, los mismos grupos municipales Popular, Socialista, y de Izquierda Unida-Los Verdes presentan de manera conjunta una «Moción sobre la provincia de Cartagena» y el acuerdo alcanzado por unanimidad en la segunda de las sesiones referidas -de 5 de marzo de 1998- es, en síntesis, el siguiente: La Corporación tomará la iniciativa en el procedimiento de creación de la provincia y para conseguir tal fin recabará y recomendará el apoyo de los Ayuntamientos limítrofes así como la información sobre el procedimiento adecuado para la convertir la «comarca» de Cartagena en provincia ${ }^{11}$.

La ausencia de la menor iniciativa para la creación de la provincia de Cartagena y sin decisión legislativa alguna por parte de la Asamblea regional al respecto así como la carencia de representación municipal del Partido Cantonal impele a calificar todas las manifestaciones corporativas referidas como de pura farsa política electoral, por un lado, y de falta de un elemental respeto a los ciudadanos provincialistas de esta ciudad, por el otro. En 1979, el Partido Socialista apoya la propuesta cantonal para no perder el apoyo de su representación municipal y con ella la Alcaldía y, desde luego, no introduce mención alguna sobre este compromiso en la elaboración del futuro Estatuto de Autonomía. El rechazo de 1997, con fundamento en el citado informe jurídico, confirma a las claras el pretexto para rechazar la provincialidad. No obstante, ante el nuevo envite electoral y conscientes de que esta manifestación podría suponer la pérdida de votos y la recuperación del Partido Cantonal, acuerdan el unánime brindis al sol del compromiso de luchar por esta causa; pero la inexistencia de dación posterior de paso alguno al respecto, aun sabiendo que una iniciativa de reforma del Estatuto se encontraba abierta y estaba a su alcance, viene a reafirmar tanto la farsa política como el engaño a la ciudadanía favorable a la provincialidad de Cartagena.

Como sucedáneo a este compromiso de lucha provincial, el gobierno regional del Partido Popular presenta a la Asamblea legislativa una Proposición no de Ley sobre la comarcalización de la Región de Murcia el 7 de mayo de 1998, un mes después del mencionado falso brindis provincial y que, como se demostrará en el epígrafe siguiente, no fue sino una hueca manifestación para camuflar la promesa política «popular» descentralizadora de Cartagena.

Así las cosas y como si nada se moviera bajo este sol veraniego abrasador, en este año previo a las elecciones locales de 2007, el Movimiento Ciudadano - representado en el Ayuntamiento con 1 concejal, frente a los 16

\footnotetext{
${ }^{11}$ Una referencia más detallada de estas dos sesiones municipales puede leerse en GARrorENA, A., $L a$ autonomía murciana, un intento de identificación, Diego Marín, Murcia, 2000, pp.80-85.
} 
LA LEGALIDAD Y VIGENCIA DE LAS ENTIDADES LOCALES TERRITORIALES...

del partido popular, 9 del partido socialista y 1 de la coalición de izquierda unida - vuelve de nuevo a agitar la llegada del Godot provincial. En su página $\mathrm{Web}^{12}$ aparecen adhesiones personales como las de los rectores de las universidades de Murcia y Cartagena, alcalde de Los Alcázares, y de la Cámara de Comercio, Industria y Navegación de la ciudad, así como informes jurídicos genéricos y referencias concretas voluntaristas y, como puede presumirse, permisivas sobre la posibilidad legal de crear la nueva provincia. Ante esta situación reiterada, hay que resaltar en primer lugar que todavía se carece de un estudio completo sobre las ventajas e inconvenientes de este desafío provincial ni, salvo error por mi parte, de una acción oficial política o administrativa que demuestre la menor iniciación de procedimiento alguno al respecto.

La demanda temática de este artículo desaconseja la inclusión de un estudio completo sobre esta reivindicación tradicional y a la vez siempre embrionaria, sin expectativas de desarrollo y desde luego de logro institucional. Las manifestaciones referidas a continuación pretenden significar ante todo un reconocimiento de este esfuerzo reivindicativo descentralizador, a pesar de mi discrepancia con la creación de la nueva organización territorial.

La legalidad constitucional posibilita la creación de nuevas provincias. Más aún, Cartagena ya fue provincia marítima desde 1799 a 1805, aunque es desconocido el deslinde territorial de ésta con la de Murcia. Incluso, adquiere el carácter general de provincia con carácter provisional desde 1821 a 1822. Ella es, religiosamente, la titular de la diócesis de Cartagena, una de las más antiguas de España, aunque parece que la bula de Nicolás IV autorizaba el traslado de sede del obispo a Murcia ante el peligro de las incursiones musulmanas. Militarmente ha sido departamento marítimo del Mediterráneo con rango de capitanía general ${ }^{13}$. Demográficamente, hay siete provincias en España con población inferior a la de su propio municipio y con sus 203.945 habitantes se convierte en la segunda municipalidad de la Región; y si es bien es cierto que Murcia-ciudad le duplica en número de habitantes, también lo es que su historia ya tenía IX siglos cuando esta capitalidad fue fundada en el año 825. Junto a estos relevantes datos, el Estatuto de Autonomía sé autodenomina de la Región de Murcia y se convierte en la única Comunidad Autónoma de España, a excepción de la de Madrid por ser la capital del Estado, que se apodera semánticamente del municipio, de la provincia y de la región. No debe resultar extraño que surja esporádicamente esta reivindicación de Cartagena ante el centralismo estatal por privarle de la condición de provincia y ante el murciano por no haberla considerado siquiera capital co-

\footnotetext{
12 www.movimientociudadano.com

${ }^{13}$ El libro de VILAR, Ma . J., Territorio y ordenación administrativa en la España contemporánea. Los orígenes de la actual Región uniprovincial de Murcia, Asamblea Regional de Murcia, 2004, refiere con mayor detalle estos datos históricos de Cartagena. Y Tornell, C., El gobierno de Cartagena en el antiguo régimen, Academia de Alfonso X El Sabio, Murcia, 2001, ofrece con detenido detalle la historia del Concejo de esta ciudad.
} 
marcal; aunque, también la propia Corporación reitere este centralismo sobre sus núcleos de población e impida cualquier entidad descentralizadora en su término municipal, como se ha ejemplificado especialmente con la creación del nuevo municipio Dos Mares.

Los defensores de la nueva provincia señalan como ventajas, de modo general y en síntesis, la mayor representación política de la Comunidad Autónoma en las Cortes, el aumento de las subvenciones estatales, la cifra obligada a favor de la nueva Diputación y, también, un mayor número de servicios estatales y locales en Cartagena. Todo esto es cierto y de modo concreto yo mismo destaqué hace sólo dos años «la desproporción comparativa debilitada existente entre el peso político parlamentario murciano, dado su número de habitantes, con el de otras Comunidades Autónomas. En este sentido, nuestra población es la mayor de las autonomías uniprovinciales, a excepción de Madrid, superando a la biprovincial Extremadura en 153.940 habitantes (1.226.993 y 1.073.050) y a la triprovincial Aragón en 9.479 (1.217.514). Contrariamente, Extremadura está representada en las Cortes durante esta VII Legislatura con 11 diputados y 10 senadores, y Aragón con 13 diputados y 14 senadores, mientras que Murcia sólo lo está con 9 representantes en la Cámara Baja y 6 en la Alta. Las cifras pues son tan desproporcionadas que ponen en entredicho y necesitado de reforma ya el carácter de circunscripción electoral de la provincia, constitucionalizado en el artículo 68.2, ya la consiguiente representación parlamentaria por la modificada Ley Orgánica del Régimen Electoral General de 1985, ya, incluso, por una reforma senatorial que convirtiera a esta Cámara en auténtica representación de las Comunidades Autónomas. La reivindicación de una representatividad más proporcional, que venga a elevar este debilitado peso político representativo de nuestra Comunidad, es justa y necesaria. Esta desmesurada debilidad política murciana, como es obvio, ha tenido y continuará acentuando en el futuro los efectos negativos estatales tanto en el poder legislativo como en el Ejecutivo, condicionados ambos por el peso electoral de las correspondientes Comunidades Autónomas» ${ }^{14}$. He de adjuntar, en este sentido, que el «Informe sobre modificaciones de la Constitución Española», realizado por el Consejo de Estado en enero de 2006, corrige parcialmente este desequilibrio representativo en el Senado con la reducción de la representación provincial.

En relación con el centralismo gubernamental murciano, que se manifiesta de modo especial en Cartagena-comarca y en Cartagena-municipio por sus características especiales de gran ciudad, lo he denunciado también por escrito recientemente. El primer extremo de ausencia comarcalizadora, de cuya temática me ocuparé en el epígrafe siguiente, la calificaba de una acción de hipocresía y de mentira de nuestros gobernantes ante la demanda estatutaria

\footnotetext{
${ }^{14}$ Martínez Marín, A., «El Gobierno y Administración de la Comunidad Autónoma de la Región de Murcia», en el libro coordinado por M. BAssols, La Administración Pública de las Comunidades Autónomas, INAP, 2004, pp. 462-463.
} 
LA LEGALIDAD Y VIGENCIA DE LAS ENTIDADES LOCALES TERRITORIALES...

y legal de comarcalizar la Región. En relación con la autonomía municipal reivindicaba la necesaria legalización de un pacto local que fortaleciese competencial y financieramente a los Ayuntamientos ${ }^{15}$.

Inmerso en esta reivindicación descentralizadora local, he de reiterar de nuevo que la creación de la nueva provincia carece de los elementales presupuestos reales para su puesta en práctica. Primero, desde 1979 ningún partido político ha realizado un estudio fundado sobre las ventajas e inconvenientes acerca de esta creación provincial, incluso su principal valedor el Partido Cantonal no sólo está incluido en esta carencia elemental del estudio previo sino que se ha autodestruido como tal, pues su desprestigio ante la ciudadanía ha determinado que carezca de representación municipal y deba camuflarse en el denominado Movimiento ciudadano. Segundo, dado que la provincia es una agrupación de municipios exigida por el artículo 141 de la Constitución, hay que dejar constancia que hasta la fecha ningún Ayuntamiento limítrofe ha manifestado su voluntad de integrarse en ésta e, incluso, en su día se manifestaron en contra de la necesaria integración. Tercero, los partidos políticos tanto los hacedores como los reformadores del Estatuto de Autonomía no han dejado siquiera huella alguna de esta reivindicación provincial en el texto estatutario. Cuarto, para que la creación sea factible es preciso que, tanto en el ámbito regional como estatal, el partido socialista como el popular estén de acuerdo en esta legalización provincial; pues dado que - ya siguiendo uno o dos procedimientos separados - esta nueva organización supone la reforma en profundidad del Estatuto, será necesaria en Cartagena la mayoría de tres quintos de la Asamblea y en Madrid la mayoría absoluta de las Cortes. Quinto, es de capital importancia tener presente que el número de las 49 provincias de 1883 sólo se ha visto alterado en 1928 con la creación de Las Palmas y, por consiguiente, alterar esta cifra será como abrir la Caja de Pandora: nuevas peticiones, reestructurar la representación de diputados y senadores de las Cortes; ampliar la Administración periférica del Estado, etc. Sexto, desde un ámbito autonómico supondría a la vez la resurrección y el nacimiento de dos Diputaciones provinciales con la consabida reestructuración de toda la Administración autonómica. Séptimo, las dos nuevas provincias significarían a su vez una reducción de las cinco circunscripciones electorales en dos. Finalmente y sin ánimo exhaustivo, las comarcas perderían toda su potencialidad como entes preceptivos - junto con los municipios - de la vertebración territorial de la Región.

El camino a reivindicar es la desconcentración de servicios de la Administración periférica del Estado bajo la dependencia del Delegado del Gobierno, la descentralización competencial de la Administración autonómica en el Ayuntamiento de Cartagena y la establecida, frustrada y adecuada comarcalización, pues volver a la provincia como Ente local es, además, una acumu-

\footnotetext{
15 Martínez Marín, A., «Año 2003: referencia legal de las entidades locales murcianas», en Anales de Historia Contemporánea, núm. 20, 2004, p. 392.
} 
lación innecesaria de estructuras, de competencias flotantes y de gastos burocráticos.

\section{Necrología de la primera propuesta comarcal de la Región}

De modo especial hemos de referirnos a la comarca y la primera dación de cuentas que hay que dar sobre ella es que en la actualidad no existe ni ley general o específica ni institución comarcal alguna en esta Comunidad Autónoma. No obstante, el Estatuto tiene preceptuado desde 1982, en su artículo 3.2, que «La Comunidad Autónoma de Murcia se organiza territorialmente en municipios y comarcas». Esta Entidad tiene pues un carácter existencial preceptivo, como sucede al menos en dos Estatutos más, el de Cataluña y el de Asturias; pues en los demás textos autonómicos, en su caso, se faculta sólo su constitución. Incluso, el preámbulo del mencionado Estatuto le atribuye una función vertebradora capital en esta geografía autonómica: «la Región de Murcia, en el pleno respeto a los derechos fundamentales y a las libertades públicas, impulsará el desarrollo de las distintas comarcas de la región sobre la base de unas relaciones armónicas que permitan terminar con los desequilibrios regionales internos». Y más aún, esta Entidad geográfica y sociológica se encuentra como «ficción», además, en múltiples textos legales de nuestro ordenamiento jurídico, como sucede con la Ley 7/1983 de Descentralización Territorial en el primero de sus artículos o, también, en la Ley 9/1984 reguladora de la Iniciativa Legislativa Popular de los Ayuntamientos y Comarcas, y desde luego en buen número de consejos consultivos comarcales en materias de sanidad, educación, etc.

Integrado en una corriente doctrinal comarcana, estudiada en gran medida por los geógrafos y economistas, he venido reivindicando, antes y después del Estatuto de 1982, la institucionalización de nuestras comarcas ${ }^{16}$. Ciertamente, la acción política y la reivindicación popular guardan silencio; pero el reclamo legal y la realidad regional siguen sosteniendo su desafío institucional y, tal vez, alguna circunstancia política-social futura provoque su institucionalización. Una de éstas ya se ha producido y aunque la incoherencia gubernamental consiguió capearla y mandarla al burladero, su referencia merece ser escrita en estas páginas preñadas de pasado; pero también oteadoras de futuro. Las líneas siguientes pretenden narrar la vida del primer intento legal de nuestra historia comarcal.

Ante la referida reivindicación municipal del Partido Popular, difícilmente viable de convertir a Cartagena en una nueva provincia, su Grupo presenta - un mes después-, como respuesta a su propio compromiso, una Propo-

\footnotetext{
${ }^{16}$ Véase Cabrera, P., Martínez Marín, A. y otros autores: La Comarca de la Vega Baja del río Segura, Universidad de Murcia, 1977; «El regionalismo murciano», ob. cit. pp. 29-30; «La Comarca: aspectos administrativos y de representación», Anales de la Universidad de Murcia, Derecho, curso 197273 (1978); y «Sólo el poder comarcal vertebrará nuestra Región», La Verdad, 9 de junio de 1994.
} 
LA LEGALIDAD Y VIGENCIA DE LAS ENTIDADES LOCALES TERRITORIALES...

sición no de ley sobre comarcalización de la Región de Murcia en la Asamblea legislativa el 7 de mayo de 1998. Los 22 votos a favor, ninguno en contra y 16 abstenciones aprueban este texto que remitía en esencia, «cual patata caliente», el desafío comarcal al estudio previo de un grupo de expertos.

La importancia histórica de la decisión legislativa me impele a citar tanto el texto literal de la Moción cuanto el calendario testifical de su falsedad:

«Primero. Instar al Consejo de Gobierno a que adopte las medidas oportunas para que se realice un estudio sobre comarcalización en la Región de Murcia, por entidades o personas físicas o jurídicas, públicas o privadas, de conocida solvencia y capacidad técnica en este ámbito, basado en los criterios a que se refiere el punto 1 del artículo 3 del Estatuto de Autonomía, como paso previo e imprescindible para acometer, con el necesario rigor, el consiguiente proyecto legislativo.

Segundo: Una vez concluido el estudio a que se refiere el punto anterior, que la Consejería competente en materia de régimen local abra un periodo de audiencia a los municipios de la región para que se manifiesten:

a) Sobre la idoneidad de los límites territoriales del proyecto de Comarca establecidos en el estudio.

b) Sobre su intención, sobre la base del punto 2 del artículo 60 de la repetida Ley de Régimen Local de la Región de Murcia, de adherirse o no al proyecto de Comarca, mediante la expresión de la voluntad de sus respectivos órganos de gobierno y representación con competencia suficiente para ello.

Tercero: Concluidos que hayan sido los trámites anteriores, el Consejo de Gobierno elaborará y enviará a la Asamblea regional un Proyecto de ley de Comarcalización en la Región de Murcia.»

El 2 de noviembre de 1998, a efectos de ejecutar el mandato del Legislativo autonómico murciano, el Gobierno considera a la Universidad como la institución adecuada para realizar este estudio y, en consecuencia, formaliza un convenio marco de colaboración entre las dos Instituciones.

El 2 de febrero de 1999, el Consejero de Presidencia y el Rector suscriben el mencionado acuerdo comarcalizador.

El 26 de octubre de 1999, el Vicerrector de Economía y Administración y, a su vez, Secretario de la Comisión Mixta de la Comunidad Autónoma y Universidad nos convoca con carácter de urgencia al Grupo seleccionado de personas para realizar el estudio. Éste está integrado por diez catedráticos y profesores titulares de las áreas de conocimiento de Historia, Geografía, Sociología, Economía y Derecho. Se adjuntan además dos secretarias para labores de apoyo y se nombra como coordinador al firmante de este artículo. 
El 23 de noviembre de 1999, celebradas múltiples reuniones tanto disciplinares como interdisciplinares, el Grupo presenta su proyecto de estudio comarcalizador (índice, miembros, coste, plazo de 14 meses de realización, publicación del trabajo como exigencia de responsabilidad de los autores, etc.) al Secretario de la Comisión Mixta.

El 27 de septiembre de 2000, el Gobierno, a través del Director General de Administración Local, comunica al Vicerrector-Secretario de la Comisión Mixta la conformidad gubernamental con la práctica totalidad de los planteamientos del proyecto, excepción hecha del importe presupuestado y por cuya causa se nos pide una reducción de la cantidad presupuestada y, a su vez, se nos ofrece la disposición de la extraordinaria cartografía regional que posee la propia Administración; siempre que esta reducción económica no suponga minoración alguna de la calidad del trabajo.

El 6 de octubre de 2000, el Grupo se reúne para estudiar las sugerencias de la Administración autonómica y por escrito remitido de esta fecha asume su deseo y reduce la cifra inicial presupuestada hasta el límite de la calidad sostenible, a efectos de que la discrepancia económica no sea causa entorpecedora de la realización de este honroso trabajo y de la colaboración entre dos instituciones al servicio ambas del interés general de nuestra Región.

El 11 de diciembre de 2000, el Gobierno, a través de la institucionalizada vía de la Dirección General de Administración Local, continúa la relación epistolar con un nuevo escrito sugiriéndonos la reducción del número de encuestas previstas y formalizándonos un ofrecimiento de recursos materiales y humanos de la propia Administración autonómica que coadyuvarían en la tarea; ...y todo ello sin que el trabajo vea menoscabada su calidad.

El 12 de enero de 2001, el Grupo comunica epistolarmente al Vicerrector-Secretario de la Comisión Mixta que la calidad convenida del trabajo desaconseja la reducción sugerida del número de encuestas y que la ayuda administrativa ofertada es en tal grado genérico que es imposible cuantificarla económicamente.

A partir de esta última fecha y hasta el momento presente, la respuesta del Gobierno ha sido el silencio absoluto.

La última noticia que poseo acerca de esta propuesta vertebradota me la ha proporcionado el Diario de Sesiones de la Asamblea Regional: el punto IV del orden del día de la sesión celebrada el día 4 de abril de 2001, página 3247, se ocupa de la «Moción 221, proyecto de ley de comarcalización de la Región de Murcia». La hueca retórica de los portavoces de los respectivos grupos parlamentarios de los partidos políticos posibilita esta síntesis simplificadora: «...nos piden plazos para realizar la comarcalización, mientras que ustedes, desde 1982 a 1995, no hablaron absolutamente de ella para nada...». 
Ciertamente no es tarea fácil esta institucionalización de vertebración comarcal y a ello se refería Barcelona Llop cuando se lamentaba de «la poca suerte que han tenido las comarcas en Cantabria, pues después de más de tres años de ser aprobada la ley ninguna se ha creado» ${ }^{17} \mathrm{o}$ en Asturias donde todavía no se ha constituido ninguna. No obstante, el Registro de Entidades Locales esperanza nuestra propuesta, pues en este año de 2006 ofrece la creciente cifra de 58 comarcas constituidas: 7 en el País Vasco, 1 en Castilla y León, 9 en Aragón, y 41 en Cataluña ${ }^{18}$.

Ante esta dilación del imperativo comarcal del Estatuto, mi pensamiento debe denunciar la ausencia de entendimiento entre los dos grandes partidos autonómicos y, de ahí, que deba reiterar el procedimiento que propusiera hace ya más de una década para superar este desafío y que literalmente se concretaba en las siguientes fases: «En primer lugar, un debate político sobre el modelo de organización regional en la Asamblea de Cartagena. En segundo término, la publicación de los acuerdos comarcales adoptados. En tercer

\footnotetext{
17 Barcelona Llop, J.: «Organización territorial: La Administración Local», en L. Martín Rebollo (editor): Derecho Público de Cantabria, Parlamento de Cantabria, 2003, p.388.

18 Algunas notas adicionales merecen ser señaladas en relación con esta primera Proposición no de ley
de creación de las comarcas en Murcia: la primera de ellas, presumible por la semántica empleada, es
que el coordinador del Grupo académico era el autor de estas páginas. La segunda anotación al respec-
to es que el procedimiento de comarcalización aprobado en la Asamblea escondía una simple salida de
la situación, pero no una metodología adecuada de trabajo para el logro del imperativo estatutario; y
sólo el sentido de la responsabilidad y de que el movimiento de descentralización comarcal se provo-
case, al menos, me hizo aceptar la honrosa invitación, aun presumiendo la consiguiente pérdida de
tiempo.
}

En apoyo de este aserto he de recordar que en 1994 ( La Verdad de 9 de junio de este año) proponía un iter procedimental que literalmente se concretaba con las siguientes fases: «En primer lugar, con un debate político sobre el modelo de organización regional en la Asamblea de Cartagena. En segundo término, con la publicación de los acuerdos comarcales adoptados. En tercer momento, con el nombramiento de una comisión de estudio, integrada por representantes de las fuerzas políticas y expertos independientes, y publicación de su trabajo. En una cuarta fase, con el anteproyecto de ley remitido a los Ayuntamientos y demás instituciones para su debate y presentación de «enmiendas». Y finalmente con la presentación del Proyecto de ley de Organización Comarcal de Murcia por el Gobierno a la Asamblea legislativa para su tramitación y aprobación definitiva». En suma, esta odisea comarcal presuponía una participación consensuada, al menos, entre los dos partidos políticos mayoritarios de la Región.

Una tercera y última anotación merece no ser omitida: la disparidad legislada de la creación comarcal entre el Estatuto que, en el mencionado artículo 3.2, la establece de modo preceptivo y general, y la del carácter facultativo de su constitución previsto en el artículo 59 de la Ley 6/1988 - «podrán crearse comarcas por Ley de la Asamblea regional»- impele a calificar este último fragmento como antiestatutario e inconstitucional en base al artículo 147.3 de la Constitución, pues la modificación de la Ley Orgánica estatutaria sólo puede realizarse por igual texto orgánico; pero no por ley ordinaria, en virtud de la reserva competencial de esta modalidad legal exigida en este mismo precepto fundamental. La Sentencia del Tribunal Constitucional 36/1981, especialmente en su fundamento jurídico 4, se pronuncia en este mismo sentido. El carácter no contingente de la provincia como Entidad local se excepciona, como ya se ha explicado y entre otros casos, en las Comunidades Autónomas uniprovinciales.

Una experiencia personal me posibilita adjuntarla a los comportamientos objetivos referidos a fin de ratificar también la ausencia de voluntad comarcalista del Partido Socialista. Derredor de 1980, el Gobierno preautonómico de este Partido me propuso de modo informal la elaboración un estudio de división comarcal; pero ante mis dos condiciones de gratuidad y publicidad de mi trabajo su respuesta guardó silencio. 
momento, el nombramiento de una comisión de estudio, integrada por representantes de las fuerzas políticas y expertos independientes, y publicación de su trabajo. En una cuarta fase, con el Anteproyecto de ley remitido a los Ayuntamientos y demás instituciones para su debate y presentación de enmiendas. Y finalmente con la presentación del Proyecto de Ley de Organización Comarcal de Murcia por el Gobierno a la Asamblea legislativa para su tramitación y aprobación definitiva». En suma, esta odisea comarcal presuponía una participación consensuada, al menos, entre los dos partidos políticos mayoritarios de la Región.

No comparto pues que la vertebración comarcal sea ya «un fracaso institucional» ${ }^{19}$, sino la reproducción en nuestro subsistema del enfrentamiento cainita entre los dos grandes partidos nacionales, movidos por una concepción patrimonialista del poder que implica tanto la destrucción del oponente como la desconsideración del interés general. Éste ha sido y continúa siendo el principal fracaso político de España y de esta Comunidad... Y los viejos, estúpidos y malvados demonios que lo han creado todavía gozan de buena salud, e incluso de excelente en el momento actual.

\section{La peculiar organización territorial-demográfica del munici- pio de Murcia}

Nuestra realidad municipal capitalina se asienta en dos bases que deben determinar su organización política-administrativa: una población derredor de los 400.000 habitantes y una distribución urbanística de capitalidad y pueblos - nuestras denominadas pedanías - que reparten la mencionada cifra aproximadamente por mitad. Esta estructura demográfica-territorial, como ya se ha escrito, la consideré modélica, hace ya varias décadas, en mi libro «Bases para un sistema autonómico comunitario del municipio de Murcia». Lamentablemente esta estructura singular heredada está a punto de desparecer a causa de la conversión de la multisecular Huerta murciana en un gran solar sobre el cual se han construido miles de viviendas, generalmente de modo caótico y despilfarrador al amparo de anacrónicos e incumplidos planes urbanísticos, que la han desfigurado hasta hacerla casi irreconocible; aunque todavía se conservan los límites, las denominaciones de las tradicionales pedanías y las conciencias sociales singularizadas ${ }^{20}$.

\footnotetext{
${ }^{19}$ Así lo denominan López Pellicer, J .A.. y Tolivar, L. en la obra coordinada por M. García CanALes y A. Garrorena, Comentarios al Estatuto de Autonomía de la Región de Murcia, Asamblea de la Región de Murcia, 2005, p. 106.

${ }^{20}$ Martínez Marín, A., Bases para un sistema autonómico..., ob. cit.
} 
LA LEGALIDAD Y VIGENCIA DE LAS ENTIDADES LOCALES TERRITORIALES...

\subsection{Las Juntas de distrito y las Juntas vecinales como respuestas institucionales a la Ley estatal básica 7/1985, a la Ley autonó- mica local de desarrollo legislativo 6/1988 y a los Reglamen- tos de Juntas de distritos urbanos, y Juntas de vecinos de pe- danías}

Al amparo de la uniforme pero simple estructura organizativa establecida en la Ley estatal de 1985 y de la autonómica de 1988, se ha venido estableciendo una adaptación y adecuación de la organización territorial municipal a nuestra singular realidad demográfica y urbanística. Durante las dos últimas décadas la Corporación municipal murciana aprobó cuatro Reglamentos — Organización y Funcionamiento de 26 de febrero de 1986, Participación Ciudadana de 9 de noviembre de 1994, Juntas de Distritos urbanos de 29 de julio de 1997, y Juntas de Vecinos de las Pedanías de 24 de febrero de 2000 - que dieron una respuesta peculiar a nuestra singularidad referida.

El municipio de Murcia estaba dividido en 8 Juntas de distrito y 58 Juntas de vecinos. Las primeras estaban integradas por varios barrios urbanos cada una, y las segundas se correspondían mayoritariamente cada una de ellas con una pedanía o pueblo — unas veces de 15.000 habitantes y otras de 1.000 separado geográficamente del casco urbano, en muchos casos, por más de una o dos decenas de kilómetros. Estas Juntas, tanto las de distrito como la de vecinos, estaban integradas por 9 miembros: presidente, vicepresidente y vocales.

La original fórmula de su elección descansaba en los respectivos partidos políticos de estos barrios y pedanías. En efecto, los afiliados políticos del respectivo partido elegían a su candidato para ocupar la presidencia de la Junta en el supuesto de que su agrupación electoral obtuviera más votos en las correspondientes elecciones municipales del respectivo distrito o pedanía, y esta votación partidista solía preceder a los mencionados comicios electorales; de tal modo que el elector municipal votaba la correspondiente lista para la Corporación municipal; pero «sabía» que con independencia de ésta, su correspondiente presidente o Alcalde pedáneo sería el propuesto por el partido político más votado en su pedanía o barrio y que los restantes miembros de la Junta también serían los propuestos por los respectivos partidos o coaliciones electorales en proporción a los votos obtenidos de conformidad con el sistema d’Hondt. De este modo, el Alcalde del municipio simplemente se limitaba a nombrar a los presidentes de barrio y pedanía -Alcalde pedáneo-, cuyo partido o coalición electoral hubiera conseguido ser la lista más votada en la elección municipal. En definitiva, los partidos políticos eran los que proponían a los presidentes, Alcaldes pedáneos y vocales en atención al porcentaje de votos obtenido en el respectivo distrito o pedanía.

Estas Juntas tenían una serie de competencias atribuidas de diverso carácter, contaban con su partida presupuestaria, y sus cargos eran honoríficos a pe- 
sar de que cada mes debían reunirse en sesión ordinaria. El presidente o alcalde pedáneo solía percibir una cantidad fija mensual en concepto de desempeño del cargo, desplazamientos, etc.

En conclusión, no se había institucionalizado la Entidad local menor; pero tampoco una pura desconcentración en cuanto eran los afiliados políticos del barrio o pedanía quienes proponían informalmente a su «alcaldable», y los electores quienes decidían en último término y de modo proporcional la propia composición de su Junta de conformidad con el resultado electoral en dicho ámbito. Tampoco nos encontrábamos ante una descentralización, en cuanto que no había una persona jurídica, dado que los recursos de alzada contra la Junta se interponían ante el Alcalde municipal. ¿Qué ha sucedido? La morfología urbanística del municipio de Murcia había acabado por establecer unas instituciones desconocidas para los principios y para las estructuras de la misma organización doctrinal administrativa. Y uno de sus resultados, desde una consideración participativa, es que más de 500 personas del municipio, integrados en estas Juntas, se ocupaban, en mayor o menor medida, de la vida de sus propios barrios y pueblos de forma gratuita.

\subsection{Las medidas básicas de organización territorial de la Ley 57/2003 de modernización del Gobierno local}

Esta original e híbrida organización territorial del municipio de Murcia podría ser cercenada o, en su caso, obstaculizada por la reciente Ley 57/2003, de 16 de diciembre, de medidas para la modernización del Gobierno local. En efecto, su artículo 128 dispone que «1. Los ayuntamientos deberán crear distritos, como divisiones territoriales propias, dotadas de órganos de gestión desconcentrada, para impulsar y desarrollar la participación ciudadana en la gestión de los asuntos municipales y su mejora, sin perjuicio de la unidad de gobierno y gestión del municipio». Esta fórmula ortodoxa de desconcentración preceptiva establece, literalmente, que nuestro municipio debería dividirse exclusivamente en distritos y que éstos habrían de sustituir a las actuales Juntas de Vecinos institucionalizadas para nuestras pedanías. Incluso, del mismo modo, este fragmento preceptúa que «3. La presidencia del distrito corresponderá en todo caso a un concejal»y, en consecuencia, nuestro histórico Alcalde pedáneo, como presidente de las referidas Juntas, deberá ser integrado en el futuro distrito y estar presidido por el consiguiente concejal de la Corporación municipal.

Estas dos nuevas exigencias básicas legales contradicen, en principio, la reglamentada organización actual. El futuro nos diría cómo habría de institucionalizar la Corporación municipal murciana este nuevo corsé «reglamentista» demandado por el legislador estatal. Nuestro parecer era contrario a esta nueva regulación por las siguientes razones: primera, limitaba la organización municipal a la sola división de distritos, no teniendo en cuenta que 
LA LEGALIDAD Y VIGENCIA DE LAS ENTIDADES LOCALES TERRITORIALES...

morfologías territoriales y sociales así como reivindicaciones democráticas podían haber determinado, como sucede en nuestro caso, otras fórmulas organizativas más adecuadas; segunda, la obligada adjudicación de la presidencia del distrito a un concejal vinculaba esta división espacial al número de ediles de la respectiva Corporación, salvo que se adjudicasen varias presidencias a uno de éstos. La coherente propuesta no podía ser otra que la modificación de esta regulación, sustituyendo el carácter preceptivo de ésta por el facultativo, como así rezaba la enmienda 236 del Grupo parlamentario socialista, y la supresión de la obligada presidencia concejil por ésta o por aquella otra que considere el reglamento de la respectiva corporación municipal. De este modo se respetaría en mayor grado la autonomía municipal para autoorganizarse territorialmente y, en nuestro caso, se lograría una mayor participación vecinal, como así se había institucionalizado con las Juntas de distrito y de vecinos ${ }^{21}$.

\subsection{El Reglamento vigente de participación ciudadana y distritos de 26 de mayo de 2005 como exigencia de la Ley 57/2003}

Nuestras presunciones no eran infundadas, el vigente Reglamento citado deroga tanto el de Participación ciudadana como el de Juntas de distrito y de vecinos, ya referidos. Más aún y desde una interpretación estricta, la reducción de las divisiones territoriales a los nuevos distritos regulados en el artículo 128 y su prevalencia sobre cualquier otra norma de igual o inferior rango establecida por la disposición adicional undécima vienen, para el municipio de Murcia, a derogar toda la regulación contenida en la Ley 6/1988 autonómica local -artículos 37 a 42 - sobre los Alcaldes de barrio, pedanías o diputaciones y sobre las Juntas de vecinos. En rigor legal, las nuevas y únicas divisiones territoriales son ya sólo los distritos, dotados de órganos de gestión desconcentrada, para impulsar y desarrollar la participación ciudadana en la gestión de los asuntos municipales y su mejora, sin perjuicio de la unidad de gobierno y gestión del municipio.

La nueva Ley para los municipios de gran población desconoce nuestro sello propio y, en puridad, lo distorsiona e incluso pervierte. En este sentido de participación territorial, las nuevas Medidas de Modernización son parcialmente de derrumbe y de obstáculo, tanto para las tenues respuestas institucionalizadas durante veinte años así como para la creación de otras nuevas adecuadas a nuestra singular realidad municipal. Esta grave aseveración predicada se encuentra fundamentada en el mismo articulado de nuevo y vigente Reglamento de 2005: el enjambre reglamentado no es ya la chapuza jurídica barroca anterior, sino el propósito camuflado del poder centralista omnímodo del Alcalde. Me limitaré a ofrecer sus principales rasgos definidores por la exigencia cuantitativa de este artículo solicitado.

${ }^{21}$ Véase nuestro artículo ya citado, «Año 2003...» pp. 385-388. 
El Reglamento se asienta, por exigencia legal, en el distrito como la división territorial propia del Ayuntamiento, cuya presidencia detenta un concejal nombrado por el Alcalde. Cada uno de estos ocho distritos está integrado de manera conjuntiva e indiscriminada por barrios y pedanías del término, «representados» éstos por una Junta municipal —nueva denominación de las antiguas Juntas de distrito de barrio y de las Juntas de vecinos de pedaníase integrados por una representación de los vocales propuestos por los partidos políticos en proporción a los resultados electorales obtenidos en dicho núcleo poblacional y que tras la elección respectiva proponen al Alcalde el futuro presidente de la propia Junta. La siguiente novedad es que todos estos presidentes de las Juntas municipales de los barrios y pedanías integran la Comisión de Coordinación de Juntas bajo la presidencia del mencionado concejal del distrito. Al dominio presidencial de éste de las respectivas Juntas municipales, se adjunta un funcionario de la Alcaldía como secretario de cada una, así como de la propia Comisión de coordinación de éstas. El resultado organizativo vigente es el de 8 distritos, integrado cada uno de éstos por un buen número de las denominadas ahora Juntas municipales y presididos por el concejal designado por el Alcalde.

Finalmente y para que todo se encuentre bien atado, ante la posibilidad existencial de una Junta municipal de un barrio o pedanía «problemática», el propio Alcalde del Ayuntamiento puede facultativamente nombrar a un Alcalde pedáneo con las competencias delegadas y medios que considere convenientes para actuar en su nombre. De este modo, el «Jefe» municipal garantiza la unidad de gobierno en todo el municipio. Adjuntar que el porcentaje mínimo de recursos presupuestarios de la Corporación que debe gestionarse por los distritos está fijado en el 8 por ciento, y que las tareas encomendadas a las Juntas son las de información de las elementales necesidades de su respectivo barrio o pedanía, y que todas ellas deben tener la bendición del concejal del respectivo distrito vienen a consumar el ahogo de cualquier decisión de estos órganos al margen de la Alcaldía.

Ante esta situación, la descentralización de este municipio sólo tiene como salida la creación de Entidades locales menores o nuevos municipios. La propuesta acerca de la necesaria solución en las primeras la formulé por escrito en mi libro ya citado de 1981 y hoy todavía la sostengo; pero ante el centralismo autoritario de la nueva Alcaldía prefiero cualquier reivindicación al silencio vecinal. La nueva Ley y el nuevo Reglamento han terminado por convertir al Alcalde en un «caudillo» especial electo, naturalmente en segunda votación en cuanto la primera la realiza el propio partido político y la ofrece a los electores en una lista completa, cerrada y bloqueada. Este sistema d'Hondt no parece querer evolucionar a un sistema mayoritario uninominal a dos vueltas; pero yo lo propongo como base de una mayor representatividad popular, de un acercamiento entre la ciudadanía con su Alcalde y sus concejales y, desde luego, como modo de aligerar la ciega disciplina impuesta por la oligarquía partidista dominadora de la confección de las listas electorales. 


\section{RELACIONES DE COLABORACIÓN DE LAS ADMINIS- TRACIONES LOCALES CON LA ADMINISTRACIÓN AUTONÓMICA: CONSORCIOS, CONVENIOS, PARTICI- PACIÓN LOCAL EN ÓRGANOS CONSULTIVOS REGIO- NALES, Y SUBVENCIONES}

Con este epígrafe de contenido material se pretende acabar el cuadro de realismo jurídico presentado de las Entidades locales de la Comunidad Autónoma en su vinculación con el Gobierno regional. Las relaciones entre las Administraciones locales y la autonómica, desde una consideración formal concretizada, se pueden observar en los consorcios existentes, en los convenios establecidos, en los órganos consultivos con presencia de representantes de ambas Administraciones, y en la dispersa acción de fomento económico consignada en los Presupuestos de la Comunidad Autónoma a favor de nuestras Entidades locales. Las líneas siguientes pretenden dejar constancia de esta realidad colaboracionista incipiente e incluso a veces sólo meramente formalista, aunque quizás vengan a reconocer de modo indirecto todas las carencias denunciadas en el trascurso de este estudio.

La Ley 7/1983, de 7 de octubre, sobre Descentralización y Colaboración entre la Comunidad Autónoma y las Entidades Locales regula de modo genérico estas relaciones mencionadas; no obstante hay que precisar que a pesar del vocablo de descentralización empleado, el propio texto legal no se refiere a este principio en su articulado e incluso confunde su noción con el de delegación en el propio preámbulo, pues afirma que «la descentralización comporta la transferencia del ejercicio de funciones, que previamente ha asumido la Comunidad Autónoma como propias». Los referidos instrumentos de colaboración los enumera el artículo 4 al establecer que la Comunidad Autónoma, previa conformidad de las Corporaciones interesadas, podrá delegarles el ejercicio de sus competencias propias; facultarles para asumir la gestión ordinaria de los servicios regionales; utilizar los órganos y medios propios de los Entes Locales para la prestación de tales servicios; colaborar con los mismos para la prestación de asistencia técnica, ayuda financiera o cualquier otra; y formalizar convenios así como constituir entes de gestión públicos o privados para la ejecución de obras, explotación de bienes o prestación de servicios de interés local o en los que coincida éste con los intereses regionales, así como instrumentar la asistencia y ayuda a estos entes. Al amparo y en el marco pues de esta Ley se han establecido las relaciones de colaboración que vamos a referir.

Salvo omisión o error, se han constituido 8 consorcios: el primero es el Servicio de extinción de incendios y salvamento de la Comunidad Autónoma de la Región de Murcia, el segundo gestiona los residuos sólidos de la Región de Murcia, el tercero tiene como finalidad el desarrollo turístico y cultural de Lorca, el cuarto establece «La Manga Consorcio», y el quinto se constituye para la promoción y desarrollo de la Comarca del Noroeste. Los 
tres últimos se han creado para el desarrollo turístico y cultural de Cartagena, para la creación y funcionamiento de un centro turístico de talasoterapia de San Pedro del Pinatar, y para adecuar y conservar como vía verde el antiguo trazado de ferrocarril Murcia-Caravaca de la $\mathrm{Cruz}^{22}$.

Hay que poner de manifiesto que el consorcio local no está de modo expreso previsto y regulado en las leyes autonómicas; sin embargo, la Ley de Bases estatal de 1985 lo contempla en su artículo 57 del modo siguiente: «La cooperación económica, técnica y administrativa entre la Administración local y las Administraciones del Estado y de las Comunidades Autónomas, tanto en asuntos locales como en asuntos de interés común, se desarrollará con carácter voluntario, bajo las formas y en los términos previstos en las leyes, pudiendo tener lugar, en todo caso, mediante los consorcios o convenios administrativos que suscriban». Sabido el diferente significado que la categoría jurídica del consorcio tiene para las diversas disciplinas legales e incluso la dispar calificación dada por algunas leyes autonómicas, como así lo ha señalado Morillo Velarde ${ }^{23}$, consideramos a los consorcios como asociaciones de personas públicas y, en su caso, también privadas para la prestación de intereses locales.

Ejemplificadamente referimos a continuación determinadas características de algunas de estas asociaciones administrativas de gestión local. El Consorcio para el Servicio de extinción de incendios y salvamento de la Comunidad Autónoma de Murcia está integrado por personas o entidades públicas que, en esta asociación, son la Comunidad Autónoma y 41 de los 45 municipios regionales, excepcionados como era presumible los mayores de Murcia y Cartagena, además de Librilla y Torre Pacheco. Su finalidad es la extinción de incendios y salvamento así como la colaboración entre los entes consorciados para la protección civil; y las aportaciones provendrán en un 51 por ciento de los gastos corrientes de la Administración autonómica y el porcentaje restante de los Entes locales en razón de los riesgos soportados. El Consorcio para el desarrollo turístico y cultural de Lorca agrupa tanto a la Comunidad Autónoma como a este municipio, pero también a la Cámara de Co-

\footnotetext{
${ }^{22}$ Los Estatutos del consorcio para el servicio de extinción de incendios y salvamento de la Comunidad Autónoma se publican por Orden de 19 de junio de 1992 (BORM de 20 de junio). Los Estatutos del consorcio para la gestión de residuos sólidos de la Región de Murcia se publican por Orden de 30 de noviembre de 1994 (BORM 14 de enero de 1995). Los Estatutos del consorcio para el desarrollo turístico y cultural de Lorca se publican por Orden de 7 de octubre de 1998 (BORM 19 de octubre). Los Estatutos de «La Manga Consorcio» lo son por Orden de 12 de abril de 1999 (BORM 19 de abril). Los Estatutos del consorcio para la promoción y desarrollo de la comarca del noroeste se publican por Orden de 3 mayo de 1999 (BORM 13 de mayo). Los tres últimos Estatutos, sin embargo, se publican por Resolución del correspondiente Secretario General y son estos: los del desarrollo turístico y cultural de Cartagena, de 18 de enero de 2001 (BORM de 5 febrero); los de cooperación económica, técnica y administrativa para el desarrollo de un centro turístico de talasoterapia en San Pedro del Pinatar, de 10 de enero de 2002 (BORM 31 de enero); y los de creación técnica, económica y administrativa del noroeste, de 7 de marzo de 2003 (BORM de 21 de marzo).

${ }^{23}$ Morillo Velarde, J. I.: «Mancomunidades y asociaciones de Entidades Locales», S. Muñoz Machado (director), Tratado de Derecho municipal, ob. cit, pp.1133-1135.
} 
LA LEGALIDAD Y VIGENCIA DE LAS ENTIDADES LOCALES TERRITORIALES...

mercio e Industria de esta ciudad y a sus organizaciones empresariales; y la finalidad es el desarrollo cultural y turístico lorquino mencionado. «La Manga Consorcio» asocia los propios municipios partícipes de este prodigio geográfico marítimo, Cartagena y San Javier, y a la Comunidad Autónoma; y su objetivo no es otro que la conjunción prestacional de estos Entes para satisfacer las necesidades de sus habitantes, deficientemente satisfechos a causa del reparto de esta unidad geográfica entre los municipios citados, y paliar de este modo la reivindicación municipalista de esta población. El Consorcio para la promoción y desarrollo del noroeste de la Región integra tanto a los cinco municipios de esta comarca geográfica como a la Confederación Regional de Organizaciones Empresariales, la Confederación Sindical de Comisiones Obreras y la Administración regional; su actividad no es otra que el seguimiento de la ejecución del Plan de desarrollo integral del noroeste murciano; y su organización, medios y actividad son mantenidos con las subvenciones y aportaciones de sus miembros.

La Administración regional, concretizando estas relaciones de colaboración referidas en la mencionada Ley 7/1983, artículo 23, como así lo ha señalado García Canales ${ }^{24}$, ha establecido numerosos convenios con las Entidades Locales con finalidades diversas. A título de ejemplo pueden citarse el Convenio tipo de colaboración entre la Comunidad Autónoma y las Corporaciones Locales de la Región en materia de disciplina de mercado y defensa de los consumidores y usuarios; el celebrado entre el Ministerio de Economía, la Consejería de Cultura y Turismo y la mancomunidad del valle de Ricote para el desarrollo de un plan de dinamización turística de este valle, o el firmado por la Consejería de Economía y Hacienda y la Federación de Municipios de la Comunidad de la Región para la extensión de la eficacia del Registro de Contratistas de esta Comunidad.

Estas relaciones de colaboración se concretan también en el ámbito de los órganos consultivos que, con carácter general o sectorial, integran a representantes de la Administración regional y de las Entidades locales. Con el mencionado carácter general de procurar la mejor intervención de los Entes locales en todas aquellas decisiones regionales que, de manera especial puedan afectarles, se creó por Ley 9/1994, de 30 de diciembre, el Consejo Regional de Cooperación Local, del que forma parte un número de Alcaldes, designados por la Federación de Municipios de la Región, igual al de representantes regionales, ostentando uno de aquellos la vicepresidencia del órgano. Las funciones de éste se extienden a la emisión de informes en asuntos de singular significación, como son los anteproyectos de leyes y decretos que de manera directa puedan incidir en las Entidades locales; atribución y delegación de competencias a las mismas; propuestas de creación y supresión de municipios o alteración de términos municipales; objetivos y prioridades que hayan

${ }^{24}$ García Canales, M.: «Comunidad Autónoma de Murcia», Enciclopedia Jurídica Básica, Madrid, 1995, p. 1302. 
de presidir la elaboración de los planes de cooperación a las obras y servicios de la competencia municipal; distribución del Fondo de Cooperación Municipal; todo lo relativo a resoluciones en materia de infraestructuras que comprendan más de un municipio y aquellas otras que, por su interés o envergadura, se considere procedente informar por cualquiera de los representantes; y sobre las previsiones de los Presupuestos generales de la Comunidad Autónoma que afecten a las Corporaciones Locales. Y junto a toda esta tarea consultiva, debe conocer las propuestas de disolución de órganos municipales, elevar su propio parecer al Consejo de Gobierno en todo lo relativo a las relaciones económico-financieras entre la Administración local y la Comunidad Autónoma; y, en todo caso, conocer e informar en cuantos asuntos convenga para la mejor coordinación entre ambas Administraciones.

Junto a este Consejo general de colaboración, existe otro gran número de órganos consultivos sectoriales en los que se persigue, en mayor o menor proporción, la representación local de este mismo principio legalizado por la citada Ley 7/1983. Ejemplificadamente pueden ser citados: El Consejo Económico y Social, creado por Ley 3/1993; el Consejo Regional de Servicios Sociales, creado por la Ley 3/2003; el Consejo Asesor Regional de Empleo y Formación, establecido por la Ley 9/2002; el Consejo de Salud de la Región de Murcia, previsto por la Ley 4/1994; el Consejo Rector del Instituto de la Mujer, contemplado en la Ley 12/2002; el Consejo Rector del Instituto de la Juventud, preceptuado por la Ley 13/2002; el Consejo Rector de Onda Regional de Murcia, constituido por la Ley 7/1994; el Consejo Escolar de la Región de Murcia, positivado en la Ley 6/1998; y finalmente y con presencia local más significada, la Comisión de Coordinación de las Policías Locales, instituido por la Ley 4/1998 de Coordinación de las Policías Locales de la Región de Murcia.

La última referencia programada ha de aludir a la consignación presupuestaria de la Comunidad Autónoma a favor de las Entidades Locales en los Presupuestos de 2003. La cifra de 107.264.469 euros es la suma destinada a favor de éstas. Con mayor o menor cantidad, todos los departamentos autonómicos, organismos e institutos subvencionan con cantidades económicas a estos Entes, ya a través de transferencias corrientes o de capital. Presidencia transfiere 42.689.034 euros en conceptos de coordinación de policías locales, Plan de Cooperación Local - 18.826.401 euros-, servicio de protección civil, consorcio de régimen de incendios y salvamento, deportes, y proyectos de iniciativas culturales y turísticas. Trabajo, Consumo y Política Social subvenciona a las Entidades Locales con 15.751.054 euros destinados a programas de asesoramiento y apoyo a la familia, y servicios sociales. Hacienda consigna 384.933 euros para el desarrollo de la comarca del noroeste. Obras Públicas, Vivienda y Transporte lo hace con 7.196.778 euros para ordenación del territorio, mejora de red viaria para transportes de viajeros y de modo específico para universitarios -1.780 .500 euros—. La Consejería de Educación y Cultura las subvenciona con 11.440.021 euros, en los progra- 
LA LEGALIDAD Y VIGENCIA DE LAS ENTIDADES LOCALES TERRITORIALES...

mas de atención a la infancia, infraestructuras educativas y culturales, inversiones en archivos y bibliotecas, rehabilitación del patrimonio artístico, y en educación de adultos y programas de garantía social -4.389 .560 euros-. Economía, Industria e Innovación destina a estas Entidades 3.538.067 euros en los conceptos de electrificación rural, seguridad minera y protección de la artesanía. Agricultura, Agua y Medio Ambiente lo hace con 1.742.167 euros para actividades en esta última materia, consorcios de residuos sólidos y urbanos, y conservación de caminos rurales. Sanidad transfiere 1.899.649 euros para prevención de drogas, inversiones en centros sanitarios y defensa del consumidor. Turismo y Ordenación del Territorio subvenciona con 8.308.842 euros para los consorcios citados y para infraestructura y equipamiento turístico. Asimismo los Institutos de la Juventud, de la Vivienda, de la Mujer e ISSORM también subvencionan a los municipios con ayudas menores, pero cuantitativamente significativas.

Las cantidades cifradas demandan, también en esta cuestión, una normativa reguladora de las subvenciones que la establezca según criterios, objetivos y procedimientos en la medida de lo posible reglados; a fin de impedir, entre otras desviaciones, el hipotético trato preferencial a los municipios gobernados por el mismo partido político. La Ley 38/2003, de 17 de noviembre, General de Subvenciones, básica en buen número de su articulado, fundamenta y a su vez impele esta demandada legislación autonómica que se produce con la Ley 7/2005, de 18 de noviembre, de Subvenciones de la CARM.

Los datos ofrecidos en este epígrafe ejemplifican de modo suficiente las diversas relaciones del Gobierno autonómico con los Entes locales y la imposibilidad autárquica de sus respectivas haciendas históricamente deficitarias; pero actualmente esta situación debe ser denunciada por su inconstitucionalidad con el artículo 142 que de modo claro e inequívoco preceptúa la autarquía financiera municipal. Esta carencia económica perniciosa viene a paliarse en muchos casos con la financiación externa proveniente de los convenios urbanísticos — iqué salida queda!—; pero esta solución les debilita ante los promotores de tal modo que éstos acaban dominando no sólo la gestión sino incluso la planificación municipal; y, en la medida que no están fijados de modo reglado estos ingresos en su recepción y en su destino, acaban convirtiéndose en una partida de mala y, en su caso, de corrupta administración. Así puede suceder y la propia vida municipal viene ofreciendo ejemplos de carestía corporativa y de enriquecimientos personales de sus propios ediles.

Admitiendo posibles errores cuánticos, las cifras concretas presupuestadas vía subvenciones confirman la debilidad de la acción municipal y supramunicipal, de un lado, y la prepotencia de la Administración regional, de otro. Los consorcios, los convenios, los conciertos y los organismos autonómicos de representación local y social están determinados en su creación y mantenimiento por la voluntad y cualificada contribución económica del Gobierno autonómico. 
La conclusión construida a lo largo de este estudio y consumada con los datos y cifras de este último epígrafe es la siguiente: el centralismo «democrático» murciano ha institucionalizado, de hecho, relaciones de dependencia impropias e incluso contrarias a las autonómicas consagradas en la Constitución, en el Estatuto y en las principales Leyes estatales y regionales.

\section{POST SCRÍPTUM: MANIFESTACIONES DEL ESPÍRITU POLÍTICO DEL SUBSISTEMA MURCIANO Y SUS SE- MEJANZAS CON EL DEL SISTEMA ESTATAL}

El libro tercero «Del Espíritu de las Leyes» de Montesquieu será la referencia genérica e ideal adoptada para reflexionar en este epílogo acerca del principio determinante que debe presidir la democracia. Las manifestaciones indiciarias de este sentimiento colectivo ayudarán a obtener un conocimiento más completo de la vida jurídica de nuestro denominado sistema democrático de las autonomías. Él autor nos dirá en qué consiste dicha vertu y la exigencia determinante de su existencia; y con este parámetro ideal se procederá a la comparación con nuestra propia realidad política manifestada en la vigencia de sus leyes y demás comportamientos determinantes y derivados de éstas. Guiados por esta brújula segura se procurará conocer la distancia que nuestro subsistema político se encuentra de su puerto moral. «La virtud política de la democracia es el amor a la patria y a las leyes. Y este amor, prefiriendo siempre el bien público al bien propio, engendra todas las virtudes particulares, que consisten en aquella preferencia». He aquí el principio del interés general como cimiento mantenedor de la democracia y el mayor o menor sentimiento que la sociedad política tenga de él nos dará la proporcionada calificación del respectivo subsistema o sistema.

La primera manifestación es obvia. Por una parte, la legislación murciana, condicionada básicamente por la estatal, supone en la historia legislativa un acontecimiento excepcional para la democracia local. Nunca nuestros municipios han tenido el grado de representatividad popular y de autogobierno que la Constitución de 1978, el Estatuto de 1982 y la propia Ley local murciana de 1988 les han garantizado. Esta competencia legislada responsabiliza a los municipios, al Gobierno autonómico y, en su caso, a la Asamblea regional para defender y promover el interés local en su existencia y en su funcionamiento. Sin embargo y por otra parte, el ejercicio de esta tarea ofrece un resultado deficitario: se ha creado un solo municipio y ocho mancomunidades municipales. El primero por empatía política y, de estas últimas, seis han sido, en puridad, de «necesaria» creación debida a la propia debilidad hacendística de las municipalidades integradas en las mencionadas mancomunidades y limitadas a la exclusiva prestación de servicios sociales. Esta aseveración denuncia pues la contradicción entre funciones municipales atribuidas y la ausencia de la correspondiente dotación económica para satisfa- 
LA LEGALIDAD Y VIGENCIA DE LAS ENTIDADES LOCALES TERRITORIALES...

cerlas y que, en último término, viene, de un lado, a continuar la histórica debilidad dineraria municipal - que ahora supone una quiebra del principio de la suficiencia hacendística local para el desempeño de sus funciones establecida en el artículo 142 de la Constitución-y, de otro, la ausencia de Pacto Local alguno de trasferencias de la Administración regional a las municipales a fin de que se produzca la demandada descentralización. En puridad pues, sólo la creación de empatía política e irregular por el Gobierno regional de Los Alcázares y la posterior de las dos mancomunidades turísticas del Mar Menor y Sierra Espuña, aun con las débiles partidas presupuestarias establecidas, es el pobre haber ofrecido por nuestros gobernantes a la diversidad demandada de Entes inframunicipales y supramunicipales en las propias leyes.

Esta pobreza creativo-asociativa trae causa del adoptado centralismo estatal por el Gobierno autonómico; pero, también, del individualismo de esta colectividad en su dimensión pública y la consiguiente ausencia reivindicativa histórica de la sociedad murciana ante el poder central y, en este caso, ante el regional. Las nuevas peticiones frustradas de descentralización se convierten al fin y al cabo, de este modo, en una prueba del centralismo regional, entendido, más que como principio de racionalidad organizativa, como una voluntad política de codicia autoritaria. Y esta inexistente vertebración institucional mantenedora del interés general autonómico-local trae causa, entre otras razones, del escaso amor político-social que nuestro desafío autonómico tuvo en sus comienzos y ha pervivido en estos últimos 25 años. Ningún estudio conjunto técnico-legislativo consensuado ha precedido ninguna de nuestras grandes leyes organizativas, a excepción del Estatuto que, de hecho, fue una carta otorgada y obligada del propio Estado de las autonomías. Más aún, la actividad de los partidos políticos murcianos no tiene tras de ellos, salvo el Partido Comunista por razón de sobrevivencia y algunas personas aisladas, rechazo de la Dictadura, reivindicación regional alguna por su autogobierno y comportamiento consensuado para enriquecerlo. Como resultado, nuestras leyes son monopartidistas y, en consecuencia, desprovistas del talento y de la voluntad de vertebrar institucionalmente la Región. Murcia ha imitado, de modo general y burdo, la tradicional hemiplejia legislativa del Estado español.

La segunda manifestación de esta idiosincrasia política murciana deriva, en consecuencia, del espíritu centralista referido. Las fuerzas electorales de esta Región y de sus principales municipios han evolucionado de modo progresivo hacia un bipartidismo, que ha posibilitado gobiernos mayoritarios socialistas y populares en estas administraciones. La gobernabilidad se ha visto asegurada de este modo; pero también ha puesto en evidencia que de modo general el espíritu de la gobernanza no ha diferido en esencia: quien ha ganado las elecciones se ha apropiado y disfrutado del respectivo botín público. Ante esta situación reiterada, el debate suele ser vacuo, demagógico y cerrado y puede reducirse a los vulgares eslóganes: nosotros somos los bue- 
nos y vosotros los malos o, este otro, si nosotros tenemos corrupción vosotros más. De este modo, los grandes proyectos que el interés general demanda se encuentran cada vez más imposibilitados en su elaboración y ejecución. Este comportamiento no puede sino alejar cada vez más a la población civil de la clase política, a excepción de las personas vinculadas interesadamente a una de las dos grandes facciones del poder público. El parecido con el ejemplo estatal es meridiano; aunque con la salvedad de que, en este caso, la existencia de representaciones nacionalistas ha venido determinando que el enfrentamiento de los dos grandes fuerzas nacionales haya llegado a tal extremo que, con la finalidad de mantener el poder y debitar al adversario, cada una de éstas haya sido capaz de aliarse con el mismo «diablo» antes que llegar al consenso parlamentario y desde luego a la gran coalición gubernamental. El problema principal de España tiene pues una naturaleza predominantemente esquizofrénica; pues cuantificando la representación parlamentaria de los dos grandes partidos, ésta ha oscilado durante las ocho legislaturas constitucionales entre el 70 y el 80 por cien, alcanzando en estas dos últimas la cifra de 308 y 315 diputados sobre el total de los 350 .

Debo pues denunciar esta falta de entendimiento entre las dos grandes partidos políticos, tanto en Murcia como, sobre todo, en España. Bastaría un breve y pasajero periodo de «convivencia» para dar solución a cualquier problema, desde la necesaria reforma constitucional hasta la elaboración conjunta de las grandes leyes elaboradas y derogadas cual tejido de Penélope. Esta situación ha llegado actualmente a una escena esperpéntica y especialmente grave para el ineludible consenso constitucional con el advenimiento del Gobierno de la facción socialista triunfante: el Pacto del Tinell, en el que expresamente el Partido Socialista excluye toda colaboración parlamentaria o gubernamental con el Partido Popular y se vincula al independentismo de Esquerra Republicana; la excepcionalidad constitucional del Estatuto de Cataluña y su consiguiente quebranto del ordenamiento jurídico vigente; la desmesurada importancia dada por el Presidente a los partidos nacionalistas, especialmente a los independentistas confesos; y las negociaciones de «paz» con el terrorismo vasco, con la consiguiente desconsideración de sus víctimas, son indicios de una hipótesis de partida para un estudio acerca de la «revancha de los vencidos» de la guerra civil que incluya la marginación política del Partido Popular. ¿Acaso no lo hizo la derecha con el alzamiento nacional, con la «santa cruzada» y con la interminable dictadura franquista? Se trataría simplemente de devolver la jugada.

La comparación del principio de la democracia de Montesquieu, como es la preferencia del interés general y del amor a la patria, con las leyes y con los comportamientos políticos del subsistema murciano y del sistema español dan como resultado una débil y quebradiza existencia democrática en España. Contrariamente, en un sentido moral la guerra no ha terminado de modo definitivo y, como escribía Julián Zugazagoitia un año antes de ser fusilado por Franco en juicio sumarísimo: «Todo hace presumir que ni los 
triunfadores fecundarán la victoria, ni los derrotados escarmentaremos en el descalabro. No hay peor enemigo del español -y de lo español- que el español mismo». Con estas lúcidas y desgarradoras palabras prologaba este socialista vasco su libro «Guerra y vicisitudes de los españoles» y este admirador suyo epiloga este artículo. 